\title{
AVALIAÇÃO ECONÔMICA DE FLORESTA DE PINUS PARA PRODUÇÃO DE MADEIRA E RESINA
}

\author{
Sidney Araujo Cordeiro - Doutorando em Ciência Florestal, Universidade Federal de Viçosa, \\ sidney.cordeiro@ufv.br \\ Márcio Lopes da Silva - Professor do Departamento de Engenharia Florestal, Universidade Federal de Viçosa, \\ marlosil@ufv.br
}

\section{RESUMO}

Analisou-se a rentabilidade de uma floresta de Pinus elliotti sob desbastes, comparando três projetos: produção de madeira; produção de madeira e resina; e produção de resina. Na produção de madeira, e de madeira e resina, foram considerados desbastes aos 8 e 12 anos, e corte final aos 21 anos. Para a produção somente de resina considerou-se desbaste aos 8 anos, sendo a resinagem a partir dos 9 anos. Os critérios de avaliação econômica utilizados foram o VPL, BPE e TIR. Pode-se concluir que os três projetos são viáveis economicamente, sendo o projeto visando à produção de resina de maior rentabilidade.

Palavras-chave: análise econômica, manejo florestal, produto florestal.

\section{INTRODUÇ̃̃̃O}

Espécies de Pinus vêm sendo plantadas, em escala comercial, no Brasil, há mais de 30 anos. Inicialmente, os plantios mais extensos foram estabelecidos nas Regiões Sul e Sudeste, com as espécies Pinus taeda para produção de matéria-prima para as indústrias de celulose e papel e Pinus elliottii para madeira serrada e extração de resina. Atualmente, com a introdução de diversas espécies, principalmente das regiões tropicais, a produção de madeira de Pinus tornou-se viável em todo o Brasil, constituindo uma importante fonte de madeira para usos gerais, englobando a fabricação de celulose e papel, lâminas e chapas de diversos tipos, madeira serrada para fins estruturais, confecção de embalagens, móveis e marcenaria em geral (Embrapa, 2009).

No Brasil, o Pinus constitui a conífera mais utilizada na produção de madeira serrada, enquanto que o mogno, o cedro e o eucalipto constituem bons exemplos de não-coníferas. A área plantada total com o gênero Pinus no Brasil atingiu 1.808.336 ha em 2007, sendo Paraná o Estado que contribuiu com o maior percentual (39\%), seguido por Santa Catarina (30\%), Rio Grande do Sul (10\%), Minas Gerais e São Paulo (8\%) e os demais estados (5\%) (ABRAF, 2008).

Os formatos e dimensões das peças de madeira serrada implicam diferentes usos, entre os quais, a produção de dormentes, madeira aplainada, beneficiada, semi-elaborada, vigas, pranchas, pontaletes, sarrafos e perfis. A indústria moveleira é o principal destino dessa produção, seguida pela construção civil e pelas indústrias de embalagem. Ainda há outros setores que utilizam os produtos provenientes da madeira serrada, como o de artefatos de madeira, decoração, artesanato e confecções de pallets, porém suas participações são pequenas no consumo total.

As exportações brasileiras de produtos florestais atingiram, em 2007, US\$ 160,6 bilhões, batendo o recorde alcançado em 2006, quando foram exportados US\$ 137,5 bilhões. A produção de madeira serrada de Pinus foi de 9,3 milhões de $\mathrm{m}^{3}$, o que corresponde a $19 \%$ do total de produtos originados a partir de madeira em tora em 2007 (Abraf, 2008). A quantidade exportada de madeira serrada de Pinus foi de aproximadamente 1,3 milhões de $\mathrm{m}^{3}$. O setor além de exportar também par- 
ticipa direta ou indiretamente de toda cadeia produtiva da madeira, impulsionando tanto o aumento na oferta de matéria-prima quanto de produtos acabados, gerando impostos e aumento da oferta de empregos diretos e indiretos.

A extração de resinas de árvores iniciou-se no Brasil na década de setenta, elevando o País à categoria de exportador do produto a partir de 1989. Apesar de ser recente a sua participação no mercado internacional, o Brasil já é o segundo maior produtor mundial da matéria-prima, com aproximadamente $90 \mathrm{mil}$ ton/ano (US\$ 25 milhões/ano), atrás apenas da China com uma produção anual de 400 mil toneladas e detentora de $60 \%$ do mercado mundial (Programa-Resina, 2003).

Além de antecipar receitas ao proprietário da floresta, a resinagem á responsável por centenas de empregos diretos, fixando o homem no meio rural. Por outro lado, gera também inúmeros empregos indiretos uma vez que a goma-resina tem várias aplicações na indústria química (Filho et al., 1992).

Nesse sentido, pesquisas que relacionem a produção de resina e de madeira serrada de Pinus são de grande importância para subsidiar projetos de produção destes produtos e contribuir para o melhor conhecimento dos produtores que já estão envolvidos nestas atividades e também aqueles que pretendem investir na produção de resina e madeira para serraria a partir de floresta de espécies do gênero Pinus.

\section{OBJETIVO}

Com base no exposto, o presente trabalho tem como objetivo estudar a rentabilidade que pode ser obtida a partir de floresta de Pinus elliotti sob desbastes, comparando três projetos: para produção de madeira; produção de madeira e resina; e produção de resina.

\section{MATERIAL E MÉTODOS}

\subsection{Produção de madeira de Pinus elliotti}

Para determinar a rentabilidade de uma floresta de Pinus visando à produção de madeira, foi considerada uma área de 1 ha, em que foram realizados dois desbastes, sendo o primeiro aos 8 anos (600 árvores), o segundo aos 12 anos (500 árvores), e o corte final aos 21 anos (500 árvores), conforme mostra quadro abaixo. O espaçamento de plantio das árvores foi de $3 \mathrm{~m} \times 2 \mathrm{~m}$, totalizando uma população inicial de 1600 árvores/ha.

Tabela 1. Estimativa de produção e preço médio da madeira de Pinus em $\mathrm{m}^{3} \cdot \mathrm{ha}^{-1}$.

\begin{tabular}{|c|c|c|}
\hline Idade & Produção $/ \mathrm{m}^{3}$ & Preço $\left(\mathrm{R} \$ / \mathrm{m}^{3}\right)$ \\
\hline 8 & 52 & 5,00 \\
\hline 12 & 72 & 15,00 \\
\hline 21 & 480 & 32,00 \\
\hline
\end{tabular}

Fonte: EMBRAPA (2009) e empresas do setor.

Tabela 2. Modelo de manejo florestal proposto para a produção de madeira.

\begin{tabular}{|c|c|c|c|c|}
\hline Idade & & $\begin{array}{c}\mathrm{N}^{\circ} \mathrm{de} \\
\text { árvores/ha }\end{array}$ & & \\
\hline Anos & $\begin{array}{l}\text { Antes do } \\
\text { desbaste }\end{array}$ & A desbastar & A resinar & $\begin{array}{l}\text { Sem } \\
\text { resinar }\end{array}$ \\
\hline 0 & 1600 & - & - & - \\
\hline 8 & 1600 & 600 & - & 600 \\
\hline 12 & 1000 & 500 & - & 500 \\
\hline 21 & 500 & 500 & - & 500 \\
\hline
\end{tabular}

Tabela 3. Itens de custo para o projeto visando à produção de madeira de Pinus.

\begin{tabular}{|c|c|c|}
\hline Atividade & Ano de ocorrência & Custo (R\$/ha) \\
\hline Implantação & 0 & 815,68 \\
Capina & 1 & 137,40 \\
Capina & 2 & 137,40 \\
Colheita (desbaste) & 8 & 258,62 \\
Colheita (desbaste) & 12 & 258,62 \\
Colheita (corte final) & 21 & 258,62 \\
Manutenção & Anual & 21,00 \\
Custo da terra & Anual & 100,00 \\
\hline
\end{tabular}

Fonte: Embrapa e empresas do setor.

\subsection{Produção de madeira e resina de Pinus elliotti}

Para determinar a rentabilidade de uma floresta de Pinus visando a Produção de madeira e de resina, foi considerada a mesma 
área citada acima, com a mesma intensidade e idade dos desbastes. A resinagem se inicia a partir do ano 9, com uma produção média de 2 kg de resina/árvore/ano (Ferreira, 2001).

Tabela 4. Modelo de manejo florestal proposto para a produção de madeira e resina.

\begin{tabular}{|c|c|c|c|c|}
\hline Idade & & ${ }^{\circ}$ de árvores/ & & \\
\hline Anos & $\begin{array}{l}\text { Antes do } \\
\text { desbaste }\end{array}$ & A desbastar & A resinar & $\begin{array}{c}\text { Sem } \\
\text { resinar }\end{array}$ \\
\hline 0 & 1600 & - & - & 1600 \\
\hline 8 & 1600 & 600 & - & 1000 \\
\hline 12 & 1000 & 500 & 1000 & 500 \\
\hline 21 & 500 & 500 & 500 & - \\
\hline
\end{tabular}

Tabela 5. Itens de custo para o projeto visando à produção de madeira de Pinus e resina.

\begin{tabular}{|c|c|c|}
\hline Atividade & Ano de ocorrência & Custo (R $\$ /$ ha) \\
\hline Implantação & 0 & 932,00 \\
Capina & 1 & 137,40 \\
Capina & 2 & 137,40 \\
Colheita (desbaste) & 8 & 258,62 \\
Resinagem & 9 & 691,88 \\
Resinagem & 10 & 691,88 \\
Resinagem & 11 & 691,88 \\
Colheita (desbaste) & 12 & 258,62 \\
Resinagem & 13 & 691,88 \\
Resinagem & 14 & 691,88 \\
Resinagem & 15 & 691,88 \\
Resinagem & 16 & 691,88 \\
Resinagem & 17 & 691,88 \\
Resinagem & 18 & 691,88 \\
Resinagem & 19 & 691,88 \\
Resinagem & 20 & 691,88 \\
Resinagem & 21 & 691,88 \\
Manutenção & Anual & 21,00 \\
Custo da terra & Anual & 100,00 \\
\hline
\end{tabular}

Fonte: EMBRAPA e empresas do setor.

\subsection{Produção de resina de Pinus elliotti}

Para determinar a rentabilidade de uma floresta de Pinus visando à produção somente de resina, foi considerada a mesma área citada acima, com um desbaste de 600 árvores aos 8 anos. A resinagem se inicia a partir do ano 9, com uma produção média de $2 \mathrm{~kg}$ de resina/ árvore/ano (Ferreira, 2001).

Tabela 6. Modelo de manejo florestal proposto para a produção de resina.

\begin{tabular}{ccccc}
\hline Idade & \multicolumn{5}{c}{$\begin{array}{c}\mathrm{N}^{\circ} \text { de } \\
\text { árvores/ha }\end{array}$} \\
\hline Anos & $\begin{array}{c}\text { Antes do } \\
\text { desbaste }\end{array}$ & A desbastar & A resinar & $\begin{array}{c}\text { Sem } \\
\text { resinar }\end{array}$ \\
0 & 1600 & - & - & 1600 \\
8 & 1600 & 600 & - & 600 \\
12 & 1000 & - & 500 & - \\
21 & 500 & - & 500 & - \\
\hline
\end{tabular}

Tabela 7. Itens de custo para o projeto visando à produção de resina Pinus.

\begin{tabular}{|c|c|c|}
\hline Atividade & Ano de ocorrência & Custo (RS/ha) \\
\hline Implantação & 0 & 932,00 \\
Capina & 1 & 137,40 \\
Capina & 2 & 137,40 \\
Colheita (desbaste) & 8 & 258,62 \\
Resinagem & 10 & 790,73 \\
Resinagem & 11 & 790,73 \\
Resinagem & 12 & 790,73 \\
Resinagem & 13 & 790,73 \\
Resinagem & 14 & 790,73 \\
Resinagem & 15 & 790,73 \\
Resinagem & 16 & 790,73 \\
Resinagem & 17 & 790,73 \\
Resinagem & 18 & 790,73 \\
Resinagem & 19 & 790,73 \\
Resinagem & 20 & 790,73 \\
Resinagem & 21 & 790,73 \\
Manutenção & Anual & 21,00 \\
Custo da terra & Anual & 100,00 \\
\hline
\end{tabular}

Fonte: Embrapa e empresas do setor.

\subsection{Critérios de avaliação econômica}

Para se fazer a avaliação econômica de um projeto, baseia-se em seu fluxo de caixa. Os métodos mais indicados para esse tipo de análise no setor florestal são os que consideram o valor do capital no tempo, pois os investimentos têm retornos em longo prazo. Os métodos que utilizados neste trabalho são: o VPL, TIR e o B(C)PE.

- Valor Presente Líquido (VPL): A viabilidade econômica de um projeto analisado pelo VPL é indicada pela diferença positiva entre receitas e custos atualizados para determinada taxa de desconto (Rezende \& Oliveira, 2001; Silva et al., 2002).

$$
V P L=\sum_{j=0}^{n} R_{j}(1+i)^{-j}-\sum_{j=0}^{n} C_{j}(1+i)^{-j}
$$

- Taxa Interna de Retorno (TIR): é a taxa de retorno anual do capital investido. $\mathrm{O}$ critério da TIR está associado a estudos de viabilidade econômica em que se busca verificar se a rentabilidade do empreendimento é superior, inferior ou igual ao custo do capital que será utilizado para financiar o projeto (Rezende et al., 2006).

$$
\sum_{j=0}^{n} R_{j}(1+T I R)^{-j}=\sum_{j=0}^{n} C_{j}(1+T I R)^{-j}
$$


- Benefício Periódico Equivalente $(\mathrm{B}(\mathrm{C}) \mathrm{PE})$ : é a parcela periódica e constante necessária ao pagamento de uma quantia igual ao VPL da opção de investimento em análise, ao longo de seu horizonte de planejamento. Este critério consiste em determinar a renda, ou benefício, se for positivo, ou o custo, se for negativo, equivalente por período de vida útil do projeto (Soares et al., 2003).

$$
(B(C) P E)=V P L\left[(1+i)^{t}-1\right] /\left[1-(1+i)^{-n t}\right]
$$

Em que:

$\mathrm{Rj}=$ valor atual das receitas no ano $\mathrm{j}$;

$\mathrm{Cj}=$ Valor atual dos custos no ano $\mathrm{j}$;

$\mathrm{i}=$ taxa de juros; $\mathrm{j}=$ período em que a receita ou custo ocorre;

$\mathrm{n}=$ número máximo de períodos; e

$\mathrm{t}=$ número de períodos de capitalização dentro do prazo de ocorrência da parcela.

A taxa comumente utilizada para avaliação econômica de atividades florestais tem variado de 6 a 12\% ao ano (Lima Júnior, 1995). Neste trabalho, adotou-se taxa de juros de $10 \%$ ao ano (taxa mínima de atratividade), já que alguns órgãos de financiamento de projetos florestais, agrícolas e ambientais adotam esta taxa de juros.

\section{RESULTADOS E DISCUSSÃO}

A partir dos dados de custos e receitas dos vários projetos florestais, foi possível elaborar um fluxo de saldos para cada projeto analisado, conforme verificado na Tabela 8 .

Os projetos têm mesma duração, são de longo prazo e apresentam elevados custos e o retorno ocorre no longo prazo.

Os três projetos analisados são viáveis do ponto de vista financeiro, o que podemos perceber de acordo com a Tabela 9.

A taxa interna de retorno (TIR) para os três projetos é maior que as taxas de desconto (10\% a.a.), sendo que a maior TIR é do projeto visando à produção de resina. Essa significativa elevação na TIR do projeto com resinagem demonstra que a atividade representa uma ex- celente alternativa capaz de alavancar a implantação de novos reflorestamentos.

Tabela 8. Fluxo de saldos para os três projetos analisados.

\begin{tabular}{cccc}
\hline & & Saldo (R\$/ha) & \\
\hline Ano & Madeira & Madeira e resina & Resina \\
\hline 0 & $-815,68$ & $-815,68$ & $-815,68$ \\
1 & $-137,4$ & $-119,36$ & $-119,36$ \\
2 & $-137,4$ & $-119,36$ & $-119,36$ \\
3 & -121 & -121 & -121 \\
4 & -121 & -121 & -121 \\
5 & -121 & -121 & -121 \\
6 & -121 & -121 & -121 \\
7 & -121 & -121 & -121 \\
8 & 1,38 & 1,38 & 1,38 \\
9 & -121 & 1208,12 & 1208,12 \\
10 & -121 & 1208,12 & 1208,12 \\
11 & -121 & 1208,12 & 1208,12 \\
12 & 821,38 & 821,38 & 1208,12 \\
13 & -121 & 258,12 & 1208,12 \\
14 & -121 & 258,12 & 1208,12 \\
15 & -121 & 258,12 & 1208,12 \\
16 & -121 & 258,12 & 1208,12 \\
17 & -121 & 258,12 & 1208,12 \\
18 & -121 & 258,12 & 1208,12 \\
19 & -121 & 258,12 & 1208,12 \\
20 & -121 & 258,12 & 1208,12 \\
21 & 15131,38 & 258,12 & 1208,12 \\
\hline
\end{tabular}

Tabela 9. Análise financeira para os três projetos.

\begin{tabular}{|c|c|c|c|}
\hline \multirow{2}{*}{$\begin{array}{l}\text { Indicadores } \\
\text { econômicos }\end{array}$} & \multicolumn{3}{|c|}{ Projetos } \\
\hline & Madeira & Madeira e resina & Resina \\
\cline { 2 - 4 } VPL (R\$/ha) & 407,42 & 619,4 & 2485,8 \\
TIR (\%) & 12 & 15 & 20 \\
BPE (R\$/ha) & 47 & 72 & 287,4 \\
\hline
\end{tabular}

O valor presente líquido (VPL) para os três projetos foi positivo, sendo que o projeto visando a produção de resina obteve maior valor, seguido do projeto visando a produção de madeira e também resina.

O BPE (Benefício periódico equivalente) também foi positivo para os três projetos, sendo maior para o projeto que visa à produção de resina.

\section{CONCLUSÃO}

Os resultados obtidos na aplicação dos critérios de avaliação econômica, Valor Presente Líquido (VPL), Benefício Periódico Equivalente (BPE), e Taxa Interna de Retorno (TIR), nos sistemas de manejo de Pinus propostos, permitem concluir que os três projetos são viáveis economicamente, sendo a ordem 
de classificação dos projetos a seguinte: produção de resina; produção de madeira e resina; e produção de madeira.

\section{AGRADECIMENTOS}

Ao Conselho Nacional de Desenvolvimento Científico e Tecnológico (CNPq) pelo apoio financeiro e à Universidade Federal de Viçosa pelo fornecimento da estrutura e pessoal.

\section{REFERÊNCIAS BIBLIOGRÁFICAS}

ASSOCIAÇÃO BRASILEIRA DE PRODUTORES DE FLORESTAS PLANTADAS ABRAF. Anuário estatístico da ABRAF: ano base 2007. Brasília: 2008, 80p.

ARESB, IPEF, IF. Programa de competitividade e produtividade do setor de gomaresina de Pinus do Brasil. Plano de ação de pesquisas - versão executiva. 2003.

EMBRAPA. Cultivo do Pinus. Disponível em: <http://www.embrapa.br> Acesso em: 02 abr. 2009.

FERREIRA, J. P. da Análise da cadeia produtiva e estrutura de custos do setor brasileiro de produtos resinosos. 2001. 105p. Tese (Mestrado em Ciências) - Escola Superior de Agricultura "Luiz de Queiroz". Piracicaba, 2001.
FILHO, A. F., MACHADO, S. A., HOSOKAWA, R. T. Avaliação econômica da resinagem em florestas de Pinus elliottii engelm. var. Elliottii. Revista Scientia forestalis, IPEF, n.45, p.48-63, jan./dez. 1992.

LIMA JUNIOR, V. B. Determinação da taxa de desconto para uso na avaliação de projetos de investimentos florestais. 1995. 90p. Dissertação (Mestrado em Ciência Florestal) Universidade Federal de Viçosa, Viçosa.

REZENDE, J. L. P.; OLIVEIRA, A. D. de. Análise econômica e social de projetos florestais. Viçosa: UFV, 2001, 389 p.

REZENDE, J. L. P.; PÁDUA, C. T. J.; OLIVEIRA, A. D. de; SCOLFORO, J. R. S. Análise econômica do fomento florestal com eucalipto no estado de Minas Gerais. Revista Cerne, Lavras, v. 12, n. 3, p. 221231, 2006.

SILVA, M. L. da; JACOVINE, L.A. G.; VALVERDE, S. L. Economia florestal. Viçosa: UFV, 2002, 178p.

SOARES, T. S.; SILVA, M. L. da; GAMA, J. R. V.; CARVALHO, R. M. M. A; VALE, R. S. do. Avaliação econômica de plantações de eucalipto submetidas a desbaste. Revista Àrvore, Viçosa, v. 27, n. 4, p. 481-486, 2003. 